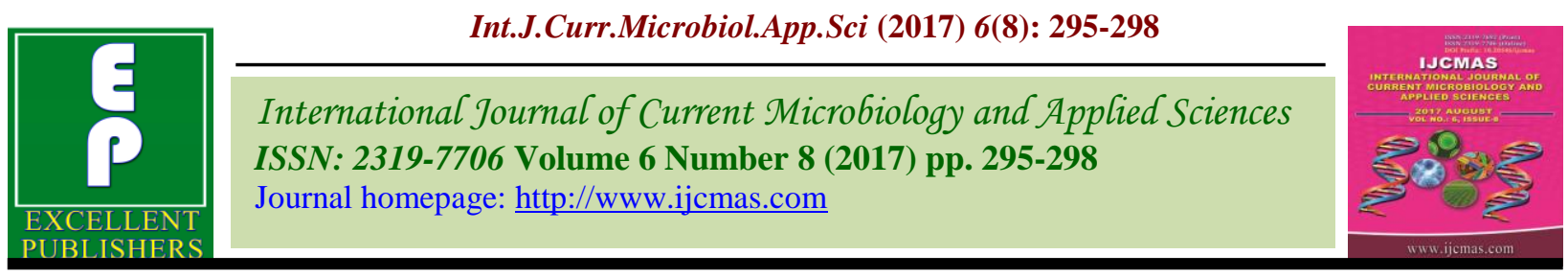

Original Research Article https://doi.org/10.20546/ijcmas.2017.608.039

\title{
Effect of In-House Training of Housekeeping Staff on Biomedical Waste Management
}

\author{
Sujitha Elan Seralathan $^{1} *$, S. Vadivu ${ }^{1}$ and S. Ravichandran ${ }^{2}$ \\ ${ }^{1}$ Department of Microbiology, ${ }^{2}$ Department of Biostatistics, Pondicherry Institute of \\ Medical Sciences, Pondicherry-605014, India \\ *Corresponding author:
}

\section{A B S T R A C T}

\begin{tabular}{|c|c|}
\hline $\begin{array}{l}\text { Ke y w or d s } \\
\text { Biomedical waste } \\
\text { management, } \\
\text { Housekeeping } \\
\text { Staff. }\end{array}$ & $\begin{array}{l}\text { Biomedical Waste (BMW) generated in health care facilities is a potential threat for the } \\
\text { personnel handling them. Utmost precaution needs to be taken by healthcare workers } \\
\text { (HCW) who handle them. In India the amount of BMW generated in a hospital ranges } \\
\text { between } 0.5-2 \mathrm{~kg} / \mathrm{bed} / \mathrm{day} \text {. According to WHO, } 85 \% \text { of the BMW generated in hospitals is } \\
\text { non- hazardous; } 10 \% \text { is infectious and } 5 \% \text { is non- infectious but according to Glenn } \text { et al, }\end{array}$ \\
\hline Article Info & amount of waste that is being generated. Healthcare personnel who handle and transport \\
\hline $\begin{array}{l}\text { Accepted: } \\
\text { 04 June } 2017 \\
\text { Available Online: } \\
10 \text { August } 2017\end{array}$ & $\begin{array}{l}\text { BMW are usually unskilled and uneducated housekeeping staff with little or no knowledge } \\
\text { about segregation and disposal of biomedical waste. Hence the study aims at the training } \\
\text { of healthcare personnel who handle BMW and to evaluate the outcome of the training. The } \\
\text { outcome has surprised and the results obtained after training were plotted. }\end{array}$ \\
\hline
\end{tabular}

\section{Introduction}

Biomedical Waste (BMW) generated in health care facilities is a potential threat for the personnel handling them. About onefourth of the BMW generated is hazardous and utmost precaution needs to be taken by healthcare workers (HCW) who handle them (Government of India, 2015). In a highly populated country like India the amount of BMW generated in a hospital ranges between $0.5-2 \mathrm{~kg} / \mathrm{bed} /$ day (Daljit et al., 2014; ENVIS, 2006). Pondicherry Pollution Control Committee states that nearly 1 ton of biomedical waste is generated in Pondicherry region every month (ENVIS, 2006; Joseph et al., 2014). According to WHO, 85\% of the BMW generated in hospitals is nonhazardous; $10 \%$ is infectious and $5 \%$ is non- infectious (New WHO Handbook on Healthcare Waste Management, 2013). However according to Glenn et al., out of the Clinical wastes generated in developing countries, the infectious waste may be as high as $35 \%$ depending on the amount of waste that is being generated (ENVIS, 2006; New WHO Handbook on Healthcare Waste Management, 2013). Even today some of the hospitals do not give much importance to the management of biomedical wastes (Daljit et al., 2014). Healthcare personnel who handle and transport BMW are usually unskilled and uneducated housekeeping staff with little or no knowledge about segregation and disposal of biomedical waste. 
To assess level of awareness about BMW management among house keeping staff in a tertiary care hospital and to evaluate the impact of 'In-House Education and Training session' on BMW management

\section{Materials and Methods}

The study was conducted in Pondicherry Institute of Medical Sciences, a tertiary care hospital in Pondicherry. The Health Care Workers (HCW) included in the study were the housekeeping staff involved in collection, segregation and disposal of BMW and were assigned to various wards, ICUs and laboratories of PIMS.

The existing level of awareness was assessed by conducting a pre-test using a validated questionnaire in vernacular language. After pre-test, the participants underwent an inhouse training session in vernacular language regarding correct methods of segregation, transport and disposal of BMW by didactic lecture followed by video show. Following the training session, a post test was conducted to know the effectiveness of the training session.

\section{Results and Discussion}

The pre-test and post-test scores were evaluated and marks scored by participants are tabulated in table 1 . Out of a total score of 10 , it was seen that $13.5 \%$ (14 out of 103) of participants scored0, $14.6 \%(\mathrm{n}=15)$ of them scored between 1to 6 and $71.9 \% \quad(n=74)$ scored between 7 and 10 . The post-test showed that no participant had scored less than 5 .

It was also observed that $15.5 \%$ of participants scored between 7 to 9 and $84.5 \%$ $(n=87)$ of them scored 10which reflects the participant's knowledge of biomedical waste management before and after the training shown clearly in the pie diagram in figure 1.

An interesting finding was that all the 14 participants who scored 0 during the pre-test showed a significant improvement with their post-test scores ranging from 7 to 10 shown in figure 2.Wilcoxon signed rank test was done which showed a $\mathrm{p}$ value $<0.0001$.

Table.1 Pre - Test and Post - Test performance

\begin{tabular}{|c|c|c|}
\hline Marks & Pre-Test (\%) & Post-Test (\%) \\
\hline Secured & 13.5 & 0 \\
\hline $1-6$ & 14.16 & 0 \\
\hline $7-9$ & 31 & 15.5 \\
\hline 10 & 40.8 & 84.5 \\
\hline
\end{tabular}


Fig.1 Knowledge of trainees (a) before the training and (b) after the training

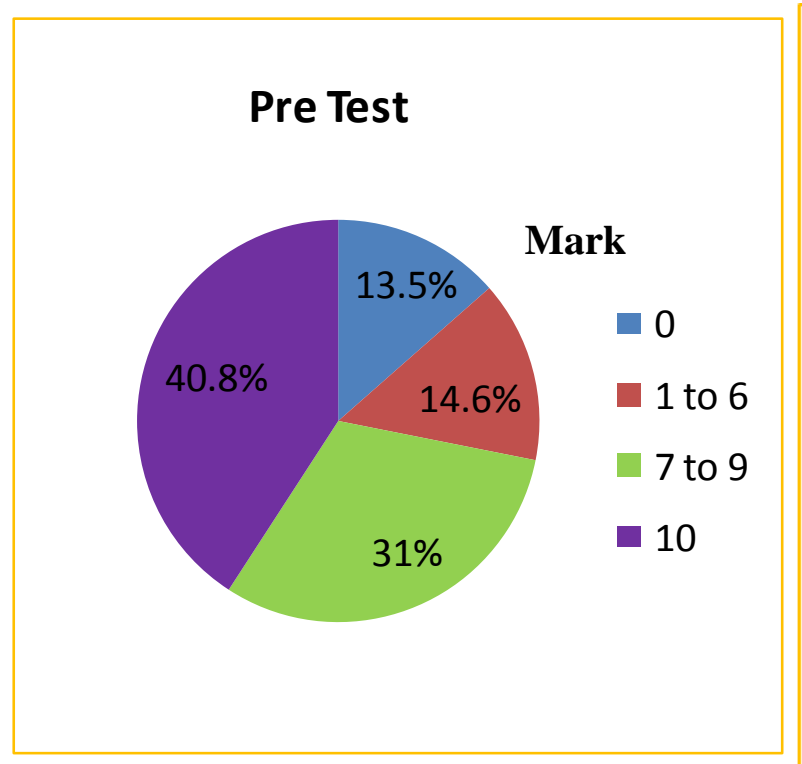

(a)

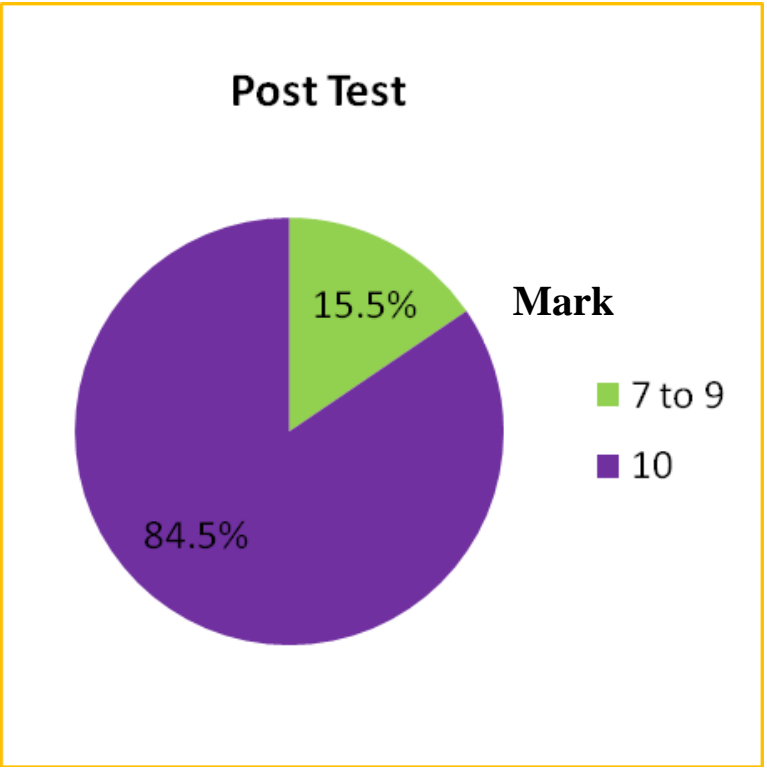

(b)

Fig.2 Improvement in post-test performance from zero marks due to In-House Training

0

In conclusion, it is necessary that regular in house training programs on BMW should be conducted primarily for the house keeping staffs who are actively involved in the 


\section{References}

Daljit Kapoor, Ashutosh Nirola, Vinod Kapoor, Ramandeep-Singh Gambhir. 2014. Knowledge and awareness regarding BMW in dental teaching institutions in India - A systematic review. J. Clin. Exp. Dent., 6(4): e41924.

ENVIS. 2006. Pondicherry Pollution Control Committee, Volume: 2, no.3, ppcc/envis/nl-4, pg.no: 1-13.

Government of India. 2015. Ministry of environment and forests, Gazette notification no: 460 , dated July 27 , New Delhi, 10-20.

Joseph, N.M., S. Elan, Vadivu, S., Kanungo, R. 2014. Infect. Control and Hospital Epidemiol., volume: 35, no.1.

New WHO Handbook on Healthcare Waste Management, August 5, 2013.

\section{How to cite this article:}

Sujitha Elan Seralathan, S. Vadivu, S. Ravichandran. 2017. Effect of In-House training of Housekeeping Staff on Biomedical Waste Management. Int.J.Curr.Microbiol.App.Sci. 6(8): 295-298. doi: https://doi.org/10.20546/ijcmas.2017.608.039 